\title{
Epistemologias negras e educação: relações étnico-raciais na formação do(a) pedagogo(a)
}

\author{
Black epistemologies and education: ethnic-racial relations in the \\ education of the pedagogue
}

\section{Epistemologias negras y educación: relacione étnico - raciales en la educación del pedagogo}

\section{Cicera Nunes"}

Universidade Regional do Cariri, Departamento de Educação, Mestrado Profissional em Educação e Mestrado Profissional em Ensino de História, Professora.

https://orcid.org/0000-0002-6352-8991

\section{Jusciney Carvalho Santana ${ }^{2}$}

Universidade Federal de Alagoas, Centro de Educação, Setor de Política e Gestão

Educacional, Professora Adjunta III.

https://orcid.org/0000-0002-6392-2876

\section{Nanci Helena Rebouças Franco ${ }^{3}$}

Universidade Federal da Bahia, Departamento I, Professora Associada III; Curso de Pedagogia e Grupo de Estudos e Pesquisas ERE, Coordenadora.

https://orcid.org/0000-0002-6810-4493

Resumo: 0 artigo tem como objetivo analisar o campo da formação em Pedagogia, a partir do reconhecimento da importância da Educação para as Relações Étnico-Raciais como elemento estruturante na construção de uma educação antirracista. Do ponto de vista metodológico é uma abordagem qualitativa de cunho bibliográfico. Inicialmente, reflete-se sobre a formação do pedagogo, a partir das determinações legais que devem fundamentar a implementação do ensino da história e cultura africana e afro-brasileira no currículo escolar - LDB 9.394/96 alterada pelas Leis 10.639/03 e 11.645/08, Resolução CNE/CP 01/2004; Parecer CNE/CP 03/2004 que institui as Diretrizes Curriculares Nacionais para a Educação das Relações Étnico-Raciais e para o Ensino de História e Cultura AfroBrasileira e Africana e o Plano Nacional para implementação dessas Diretrizes (2009). Aborda-se a importância da construção de espaços de produção de conhecimentos que questionem as bases do

Doutora em Educação Brasileira pela Universidade Federal do Ceará; Mestre em Educação Brasileira pela Universidade Federal do Ceará.

2 Doutora em Educação Brasileira pela Universidade Federal da Bahia; Mestre em Desenvolvimento Humano e Responsabilidade Social pelo Centro de Pós-graduação e Pesquisa Fundação Visconde de Cairu.

3 Pós-doutora em Sociologia da Educação pela Universidade do Minho, Portugal; Doutora em Educação pela Universidade Federal de Alagoas. 
pensamento racista no Brasil na perspectiva discutida por Gomes (2012), partindo da construção de propostas comprometidas com a superação do racismo e que apontem para um novo paradigma de educação. As reflexões propostas por Carneiro (2005), Rodrigues, Cardoso e Silva (2019), Petit (2015, 2016), Gonçalves e Silva (2007), questionam o epistemicídio e colaboram para repensar a formação em pedagogia enquanto espaço importante de construção de referenciais teórico-metodológicos e de reconhecimento das epistemologias negras, apontando possibilidades de ressignificações curriculares e pedagógicas. Com isso, reconhece-se que uma mudança epistemológica e a descolonização dos currículos são parte das mudanças necessárias no campo da formação dos profissionais da educação e, em especial, dos(as) pedagogos(as).

Palavras-chave: Epistemologia negra. Formação inicial e continuada. Pedagogia. Relações étnico-raciais.

Abstract: The article aims to analyze the field of Pedagogy Education based on the recognition of the importance of Education for Ethnic-Racial Relations as a structuring element in the construction of anti-racist education. From a methodological point of view, the study uses a qualitative approach of a bibliographic nature. Initially, it reflects on the education of the pedagogue through the legal determinations that should support the implementation of the teaching of African and Afro-Brazilian history and culture in the school curriculum. This legal framework - LDB no. 9.394/96, amended by Laws no. 10.639/03 and no. 11.645/08, Resolution CNE/CP no. 01/2004, Decision CNE/CP no. 03/2004 - established the National Curriculum Guidelines for the Education of Ethnic-Racial Relations and the Teaching of Afro-Brazilian and African History and Culture, in addition to the National Plan for the implementation of these Guidelines (2009). The study addresses the importance of constructing spaces for the production of knowledge that questions the foundations of racist thought in Brazil from the perspective discussed by Gomes (2012), starting from the construction of proposals committed to overcoming racism and pointing to a new paradigm of education. The reflections proposed by Carneiro (2005), Rodrigues, Cardoso and Silva (2019), Petit (2015, 2016), Gonçalves and Silva (2007), question the epistemicide and collaborate to rethink training in pedagogy as an important space to build theoretical-methodological references and recognize black epistemologies, pointing out possibilities for curricular and pedagogical resignifications. As such, it is recognized that an epistemological change and decolonization of curriculums are part of the necessary changes in the training of education professionals and especially of pedagogues. Keywords: Black epistemology. Initial and continuing education. Pedagogy. Ethnic-racial relations.

Resumen: El artículo tiene como objetivo analizar el campo de la formación en Pedagogía, a partir del reconocimiento de la importancia de la Educación para las Relaciones Étnico-Raciales como elemento estructurante en la construcción de una educación antirracista. Desde un punto de vista metodológico, es un enfoque cualitativo de carácter bibliográfico. Inicialmente, se refleja en la formación del pedagogo, a partir de las determinaciones legales que deben sustentar la implementación de la enseñanza de la historia y cultura africana y afrobrasileña en el currículo escolar - LDB 9.394 / 96, modificada por las Leyes 10,639/03 y 11.645 / 08, Resolución CNE / CP 01/2004, Dictamen CNE / CP 03/2004 por el que se establece los Lineamientos Curriculares Nacionales para la Educación en Relaciones Étnico- 
Raciales y para la Enseñanza de la Historia y Cultura Afrobrasileña y Africana y el Plan Nacional para la implementación de estos Lineamientos (2009). Se aborda la importancia de construir espacios de producción de conocimiento que cuestionen las bases del pensamiento racista en Brasil desde la perspectiva discutida por Gomes (2012), partiendo de la construcción de propuestas comprometidas con la superación del racismo y apuntando a un nuevo paradigma de educación. Las reflexiones propuestas por Carneiro (2005), Rodrigues, Cardoso e Silva (2019), Petit (2015, 2016), Gonçalves y Silva (2007), cuestionan el epistemicidio y colaboran para repensar la formación en pedagogía como un importante espacio de construcción de referencias teórico-metodológico y reconocimiento de las epistemologías negras, señalando posibilidades de resignificaciones curriculares y pedagógicas. Así, se reconoce que un cambio epistemológico y la descolonización de los planes de estudio son parte de los cambios necesarios en el campo de la formación para los profesionales de la educación, y en particular para los pedagogos.

Palabras clave: Epistemología negra. Educación inicial y continua. Pedagogía. Relaciones étnico-raciales.

Recebido em 14 de setembro de 2020 Aceito em 15 de março de 2021

\section{INTRODUÇÃO}

Historicamente as organizações dos movimentos negros têm questionado as bases epistemológicas dos currículos escolares e denunciado a escola e a universidade como instituições reprodutoras do racismo. Como desdobramento desse processo temos a alteração na Lei de Diretrizes e Bases da Educação Nacional, LDB n. 9.394/96 (BRASIL, 1996), com a promulgação da Lei $n^{\circ}$. 10.639/03 (BRASIL, 2003), que tornou obrigatório o ensino da história e cultura africana e afro-brasileira e, em 2008, a inclusão da Lei $n^{\circ}$. 11.645/08 (BRASIL, 2008) que define a obrigatoriedade do ensino da história e cultura indígena em todo o currículo escolar.

As reflexões em torno dessa política curricular, para além do cumprimento legal, questionam a concepção de educação e propõem uma mudança estrutural, conceitual, epistemológica e política que atinja, de forma positiva, a sociedade com a construção de propostas comprometidas com a superação do racismo (GOMES, 2012).

É nesse contexto que as universidades são chamadas a se posicionar, pois entende-se que uma mudança epistemológica que contribua para a descolonização dos currículos e questione as bases do pensamento racista no Brasil passa necessariamente por uma reflexão no campo da formação dos profissionais da educação. 0 Conselho Nacional de Educação, através da Resolução n. 01/2004 (art.1) orienta que as Instituições de Ensino Superior incluam "[...] nos conteúdos de disciplinas e atividades curriculares dos cursos que 
ministram, a Educação das Relações Étnico-Raciais, bem como o tratamento de questões e temáticas que dizem respeito aos afrodescendentes [...]" (BRASIL, 2004).

0 documento do Conselho Nacional de Educação ainda ressalta a necessidade do incentivo à produção de pesquisas sobre processos educativos orientados por valores, visões de mundo, conhecimentos afro-brasileiros e indígenas, bem como orienta a criação de grupos de estudos e pesquisas que atuem no sentido de ampliar as bases teóricas sobre o tema e que ofereçam suporte para a reformulação de planos institucionais, projetos pedagógicos e de ensino numa interlocução direta com as produções das organizações dos movimentos negros e com experiências de formação comprometidas com a educação das relações étnico-raciais.

Nesse contexto os cursos de Pedagogia tornam-se parte importante nesse processo, pois a formação direcionará o profissional para atuar nas práticas de docência, em especial na educação infantil e nos anos iniciais do ensino fundamental $\left(1^{\circ}\right.$ ao $5^{\circ}$ ano) e para a gestão educacional, onde terá a oportunidade de desenvolver um trabalho voltado para a educação das relações étnico-raciais na infância, bem como atuar na aplicabilidade dessa política nos espaços escolares.

Reforçam as Diretrizes Curriculares para o curso de Pedagogia que as atividades docentes também envolvem a participação na organização e gestão dos sistemas e instituições de ensino levando o egresso do curso a estar apto, dentre outras questões a "demonstrar consciência da diversidade, respeitando as diferenças de natureza ambientalecológica, étnico-racial, de gêneros, faixas geracionais, classes sociais, religiões, necessidades especiais, escolhas sexuais, entre outras." (BRASIL, 2006, Art. 5, inciso 9).

Desse modo, o presente artigo tem como proposta analisar o campo da formação em pedagogia, a partir do reconhecimento da importância da Educação para as Relações Étnico-Raciais na Educação (ERER) como elemento estruturante na construção de uma educação antirracista, e, nesse contexto, apontar caminhos para uma formação que considere as epistemologias negras como parte fundamental na construção de uma educação antirracista.

Isso significa a ERER permear todo o currículo, possibilitando ao professor em formação o conhecimento da história e cultura africana e afro-brasileira no espaço da Universidade, o que vai viabilizar a construção de subsídios teóricos-metodológicos de reconhecimento do legado afro-diaspórico.

Ressalta-se que do ponto de vista metodológico, o estudo parte de uma abordagem qualitativa de cunho bibliográfico, centrada na literatura clássica, bem como novos autores que tratam sobre o tema, além de documentos legais essenciais para discutir a formação do pedagogo para a ERER. 
A formação em Pedagogia pressupõe considerar, na concepção desta licenciatura, diversos saberes para além da docência, uma vez que o profissional egresso poderá atuar em espaços escolares e não escolares. Para tanto, deve ser priorizada a construção de conhecimentos pautados na ética e na perspectiva de contribuir para redução das desigualdades educacionais, sociais e étnico-raciais persistentes em todos os níveis da educação pública, desde a educação infantil, em todas as regiões brasileiras. 0 parecer orienta ainda que na organização curricular do curso de Pedagogia devem ser observados, com especial atenção, os princípios constitucionais e legais, dentre esses, o reconhecimento da diversidade social, étnico-racial e regional do país (BRASIL, 2006).

Agir, portanto, é o que demanda a temática e consiste no convite do nosso tempo, com vistas a "alterar visões de mundo, redimensionar a memória, criticar mitos e enfrentar preconceitos." (COELHO; COELHO, 2013, p. 71). Wilma Coelho (2018) ao se referir a pesquisa realizada sobre o percurso da literatura especializada - artigos publicados em revistas entre A1 a B5, 8 teses e 22 dissertações, produzidas entre 2003/2014 - que trata sobre a Formação de Professores e Relações Étnico-Raciais, mostra que a referida literatura conformou um campo de pesquisa, mas pontua que ainda é necessário caminhar no campo das práticas e para tanto orienta que é preciso "rever currículos, repensar pesquisas, problematizar aportes, criticar lugares consagrados, desafiar os cânones são algumas das dimensões deste desafio." (COELHO, 2018, p. 97).

\section{A FORMAÇÃO DO PEDAGOGO E AS RELAÇÕES ÉTNICO- RACIAIS}

Uma mudança epistemológica que contribua para a descolonização dos currículos nas escolas brasileiras passa necessariamente por uma reflexão no campo da formação docente. Nas Diretrizes Curriculares para o curso de Pedagogia (BRASIL, 2006) está colocado a compreensão da docência enquanto uma ação intencional que se constrói no contexto das relações sociais, étnico-raciais, produtivas, bem como no âmbito do diálogo entre diferentes visões de mundo.

Nesse contexto o campo da teoria educacional ao tempo em que dialoga com a diversidade epistemológica deve refletir a ausência de referenciais que partam das visões de mundo dos povos africanos e da produção do conhecimento no contexto afro diaspórico. Para Carneiro (2005) o epistemicídio anula e desqualifica o conhecimento dos povos subjugados, seja pela negação do acesso à educação escolarizada, seja pelos diferentes mecanismos de 
deslegitimação do povo negro como produtor de conhecimento e de rebaixamento da capacidade cognitiva que se processa pela carência material e pelo comprometimento da autoestima.

Os cursos de Pedagogia tornam-se parte importante desse processo, pois devem fomentar e fortalecer o debate acadêmico no enfrentamento ao racismo, ao garantir a inclusão na estrutura curricular dos cursos e na proposição de ações afirmativas, nos espaços da formação de parte importante dos (as) professores (as) da educação básica, compreendendo os diferentes alcances nos eixos de ensino, pesquisa, extensão e gestão.

Para Luz (2019) embora se reconheça os avanços político-institucionais no âmbito curricular nos anos mais recentes do Brasil, é importante destacar que ainda não foi possível eliminar todas as dificuldades no panorama geral dos programas de ensino e nas práticas de sala de aula do país sobretudo quanto aos pertencimentos étnico-raciais. Segundo o autor os processos de crítica do mundo tendem a cada vez mais se expressar na reflexão sobre a importância do conhecimento histórico junto aos sistemas educacionais "[...] de modo a transformar a representação sobre o papel da África e dos descendentes de africanos na história do mundo." (LUZ, 2019, p. 577).

Essas demandas apontam para o reconhecimento da distância ainda existente entre a prática educativa e o que está preconizado nos marcos legais da educação brasileira, uma vez que as instituições de educação superior, responsáveis pela formação inicial de professores (as), ainda não procederam, de forma radical, na incorporação das transformações curriculares necessárias, que permitam romper com a perspectiva eurocêntrica referenciada nesse nível de escolarização, o que vai impactar diretamente na formação e consequentemente no alcance da ERER na educação básica.

Além dessas duras constatações, também não é verificável o engajamento necessário entre os entes federados, com investimento efetivo em novas políticas de formação continuada com ênfase em diversidade étnico-racial na educação, o que limita, por conseguinte, a capacidade de transformar processualmente a atuação dos profissionais da educação, em exercício, na rede pública de ensino. Mesmo as Secretarias de Educação que têm legislação específica sobre formação continuada, não têm dado conta de garantir aos seus professores esse direito; isso, no que diz respeito a qualidade e quantidade da formação ofertada, atendendo às necessidades e expectativas dos professores, o que poderia se traduzir em práticas promotoras da igualdade racial.

Assim, apregoa-se que o espaço da escola pode se construir como espaço pedagógico por excelência, reelaborando os conhecimentos acumulados na formação inicial a partir do vivido/construído no chão da escola, com mediação do pedagogo - responsável pela formação em serviço - no que diz respeito a ERER desde a Educação Infantil - uma vez 
que a escola tem se apresentado como sendo o primeiro espaço formal em que as crianças têm as primeiras experiências de discriminação racial.

Santos (2015) discute que o currículo precisa dialogar com a dimensão identitária dos sujeitos que compõem a Instituição (crianças e adultos), que é necessário repensar as práticas pedagógicas e de gestão cristalizadas - carregadas de preconceito e diversas formas de discriminação, bem como a importância de visibilizar o papel político dos (as) professores (as), possibilitando sua participação na construção de políticas públicas que atendam as crianças negras com mais qualidade e equidade. A reescrita da história da população negra depende de uma mudança de mentalidade a partir do entendimento de que a educação deve contribuir para elevar a condição humana e ser instrumento de transformação social.

Conforme Macedo (2005) a escola e os espaços de formação docente precisam reconhecer as diferenças, mas também criar situações para que se estabeleçam relações entre as pessoas e suas diversas experiências de mundo. A autora alerta que é preciso romper com uma concepção de educação que historicamente tem defendido uma uniformidade de aprendizagem e de culturas, o que tende a desqualificar os que não seguem essas referências reiterando a dominação e a reprodução de desigualdades educacionais e raciais.

A bandeira de luta pelo direito à educação sempre foi uma prioridade na história dos movimentos sociais e em específico dos movimentos negros. Gomes (2017, p. 14), no livro "Movimento Negro Educador" discute que esse movimento é um "produtor de saberes emancipatórios e um sistematizador de conhecimentos sobre a questão racial no Brasil. Saberes transformados em reivindicações, das quais várias se tornaram políticas de Estado nas primeiras décadas do século XXI." A autora coloca o Movimento Negro Brasileiro como um ator político, como um novo sujeito, e destaca algumas reivindicações desse movimento por educação que sai do momento da denúncia para a cobrança, intervenção do Estado e construção de políticas públicas de igualdade racial.

Exigir a garantia de oportunidades iguais e do direito à educação pressupõe, por sua vez, a implementação das políticas públicas afirmativas com destaque para as cotas raciais - garantindo o acesso, bem como a permanência material e simbólica dos estudantes. E finaliza afirmando que o movimento a partir de 2000 tem como estratégia de ação a implementação de políticas de igualdade racial.

0 professor Kabengele Munanga em entrevista concedida à Luciane Ribeiro Dias Gonçalves (2013) reforça que os (as) educadores (as) que foram formados (as) numa visão monocultural, eurocentrada e que viveram suas relações cotidianas dentro do universo racista precisam ser educados (as) para enxergar e sentir a diferença de culturas e civilizações que formam o povo brasileiro. Gonçalves (2013) alerta que significa se abrir para 
o diálogo com as demais culturas que formam a identidade nacional e, nesse contexto, a formação docente, enquanto política pública, é prioritária. Apesar da formação centrada em uma história única, e por isso, carregada de incompletude, professores individualmente ao longo dos anos vêm produzindo experiências exitosas de conhecimento da história e cultura africana e promotoras da igualdade racial, desde a educação Infantil, como as socializadas pelo Centro de Estudos das Relações de Trabalho e Desigualdades (CEERT), ${ }^{4}$ e essas iniciativas insurgentes devem ser consideradas.

Nesse processo, uma medida afirmativa essencial será oferecer uma formação aos (as) educadores (as) que os permita reconhecer todas as matrizes formadoras da sociedade brasileira - africana, indígena e europeia, bem como reconhecer que a presença dos povos africanos e seus descendentes no Brasil é uma história de violências, lutas e resistências que vai além do período da escravização. Isso significa assumir um patrimônio histórico e cultural que é plural e acessar as contribuições significativas desses povos no avanço da sociedade brasileira em todas as dimensões.

Os documentos que fundamentam a obrigatoriedade do ensino da história e cultura africana e afro-brasileira no currículo escolar - Lei $n^{\circ}$. 10.639/03, Lei n. 11.645/08, Parecer CNE/CP n. 03/2004, Resolução CNE/CP 01/2004, Plano Nacional de implementação das Diretrizes Curriculares Nacionais para a Educação das Relações Étnico-Raciais e para o Ensino de História e Cultura Afro-brasileira e Africana (BRASIL, 2009) - impactam diretamente nos programas dos cursos de formação inicial e continuada dos professores. Nesse sentido, fica explícita a responsabilidade das Instituições de Educação Superior para priorizar e garantir a ERER e outras ações afirmativas que valorizem e considerem as populações negras e indígenas como constituintes da formação do povo brasileiro.

0 Plano Nacional de implementação das Diretrizes Curriculares Nacionais para a Educação das Relações Étnico-Raciais e para o Ensino de História e Cultura Afro-brasileira e Africana (BRASIL, 2009), nas orientações sobre as principais ações das instituições de educação superior destaca a importância da produção de conhecimento, o incentivo à pesquisa com a inserção dos estudantes de graduação em experiências de iniciação científica que abordem a temática, bem como a importância de ações em parceria com as secretarias de educação e escolas de educação básica em seus projetos de pesquisa e extensão.

Uma iniciativa importante para o engajamento dos estudantes em pesquisa nas universidades federais é o Programa Institucional de Iniciação Científica em Ações Afirmativas (PIBIC-AF), um programa de bolsas destinado a estudantes que ingressaram na Universidade 
a partir das ações afirmativas e que possibilita iniciação cientifica e tecnológica dos mesmos, e a depender do tema/questão de investigação, uma aproximação da universidade com a ERER nas escolas.

Ressalta-se que a existência dos documentos legais não alterou significativamente a formação docente no que diz respeito a ERER. A Universidade continua desempenhando as suas funções precípuas de ensino, pesquisa e extensão ainda deslocadas dos debates feitos por novos sujeitos que vêm adentrando os seus espaços nos últimos anos. Por conta disso, não há uma política institucional de formação inicial e continuada dos (as) professores (as), e em específico dos (as) pedagogos (as), sobre essa temática, em muitas universidades brasileiras. No entanto, reforçam Rodrigues, Cardoso e Silva (2019, p. 2) que:

\footnotetext{
A universidade de hoje, que se constituiu durante o século XX, dedicada à formação de uma elite intelectual, oriunda de grupos historicamente privilegiados, capaz de influenciar os destinos da sociedade ou privilegiar apenas um determinado grupo, já não se sustenta mais na contemporaneidade; precisa atualizar-se a partir da demanda e do direito à diferença.
}

A pesquisa de Corenza (2018) aponta a deficiência na formação inicial de professores (as) para trabalhar com ERER. Para tanto, levanta alguns questionamentos: Como a Lei n. 10.639/2003 é aplicada nos cursos de Pedagogia? Qual a contribuição teórica e prática desse debate na formação inicial? Quais as disciplinas que trabalham tal temática no curso? Essas disciplinas contribuem na reelaboração de conceitos? A autora destaca a importância da oferta de uma disciplina, a existência de grupo (s) de pesquisa, a realização de eventos internos na universidade, bem como a participação em palestras, feiras e congressos que tratam sobre relações raciais.

Passos (2014) em estudo que analisou os projetos pedagógicos dos cursos de Pedagogia de dez universidades catarinenses em 2011 constata que as universidades analisadas não haviam apresentado resultados satisfatórios na inserção dos conteúdos requeridos pela legislação antirracista, que os conteúdos relativos à educação das relações étnico-raciais ocupavam lugares periféricos no currículo, ainda que tenha se passado dez anos da alteração na LDB nº 9.394/96.

Esse cenário nos leva a refletir a forma como essa temática tem sido normalmente trabalhada nos cursos de formação de professores (as) e especialmente nos cursos de Licenciatura em Pedagogia - projetos de pesquisa, grupos de pesquisa e de estudos, componentes curriculares obrigatórios e/ou optativos, cursos de extensão, eventos abertos a população, entre outras atividades curriculares e extracurriculares, normalmente construídas por professores(as)/pesquisadores(as) negros(as) e outros(as)que 
têm um comprometimento político com as discussões supracitadas. Assim, a formação inicial vem ocorrendo, a partir das pautas estabelecidas pelos intelectuais negros e negras que compõem a universidade brasileira que buscam atrelar "ação engajada da ciência com as lutas sociais dos negros" (DAMĨ̃O; ARAUJO, 2019), e dos seus pares pesquisadores(as), bem como das pautas apresentadas pelas organizações dos movimentos negros.

É importante destacar que a ampliação do acesso dos(as) estudantes negros(as) às universidades a partir das políticas de ações afirmativas também explicita que essas instituições não se prepararam do ponto de vista das políticas de permanência material, nem de permanência simbólica para acolher os diferentes sujeitos que adentram esses espaços. Com isso, esses(as) estudantes(as) tensionam seus processos de formação, buscando se reconhecer no currículo instituído.

Para Rodrigues, Cardoso e Silva (2019, p. 2) as instituições de educação superior são desafiadas pelas políticas de ações afirmativas a produzir ciências e pluralizar conhecimentos que alterem os padrões desiguais e discriminatórios. Para as autoras essa demanda nos leva a compreender o campo da "[...] a formação de professores como um campo estratégico para romper a herança colonizadora que estrutura a sociedade brasileira, sendo a escola um dos lócus de produção e reprodução desse sistema."

Diante do exposto, Gomes (2009) reforça que é necessário mobilizar a sociedade civil para que compreenda a diversidade étnico-racial como um direito que deve ser garantido nas escolas, nos currículos, nos projetos político-pedagógicos, na formação de professores, nas políticas educacionais. Num plano mais amplo implica que é afirmar que:

\footnotetext{
A inserção da questão racial nas metas educacionais do país, no Plano Nacional de Educação, no Plano de Desenvolvimento da Educação, nos planos estaduais e municipais, na gestão da escola e nas práticas pedagógicas e curriculares de forma mais contundente. Significa, portanto, a realização de uma mudança radical nas políticas universalistas, a ponto de qualquer iniciativa de política pública em educação no Brasil passar a incorporar explicitamente a diversidade étnico-racial. (GOMES, 2009, p. 41).
}

Não podemos, enquanto coletivos, validar uma educação que não cumpra seu papel social de garantir o exercício da autonomia, de estimular a participação ativa de seus atores e do exercício da democracia como condições essenciais, para que escolas e universidades possam construir suas propostas políticas e pedagógicas que traduzam o objetivo de contribuir para a emancipação dos sujeitos, como princípio basilar e inegociável.

Portanto, considerar, respeitar e valorizar uma educação para as relações étnico-raciais, implica romper com uma estrutura curricular eurocêntrica, investindo em novas contribuições sobre a história e a cultura africana e indígena, conforme preconizadas na LDB 
alterada nos anos 2003 e 2008. A atuação dos (as) professores (as) será muito relevante e, para isso, será necessário estar aberto a um novo aprendizado, a problematizar conjunturas e teorias, a redescobrir o mundo no diálogo com os (as) seus (as) educandos (as) (VIDEIRA, 2009).

Gonçalves e Silva (2007) ressaltam que as DCNs para a educação das relações étnico-raciais e para o ensino de história e cultura afro-brasileira e africana (BRASIL, 2004) nos lembram que a educação das relações étnico-raciais deve ser conduzida tendo-se como referência os seguintes princípios: "consciência política e histórica da diversidade, fortalecimento de identidades e de direitos e ações educativas de combate ao racismo e às discriminações." Com isso, reforça a autora, desencadeiam exigências éticas, epistemológicas e pedagógicas, o que nos instiga ao estudo dos conhecimentos de base africana ressignificados no contexto brasileiro, a conhecer a história de luta e resistência da população negra, bem como o reconhecimento das suas principais reivindicações no campo da luta antirracista.

No contexto da educação das relações étnico-raciais deve-se assumir o compromisso com a formação de mulheres e homens que estejam comprometidos com as questões de interesse geral, mas também capazes de:

[...] reconhecer e valorizar visões de mundo, experiências históricas, contribuições dos diferentes povos que têm formado a nação, bem como de negociar prioridades, coordenando diferentes interesses, propósitos, desejos, além de propor políticas que contemplem efetivamente a todos. (GONÇALVES; SILVA, 2007, p. 490).

A escola tem a responsabilidade de construir significações positivas das populações negras e desenvolver ações que promovam o respeito à diversidade cultural e histórica, desde os primeiros momentos de contato da criança com a escola. Para que isso ocorra, é parte importante desse processo repensar os processos de formação inicial e continuada dos profissionais da educação básica.

Nesse contexto é importante considerar o papel do núcleo gestor na condução das políticas antirracistas em âmbito escolar. Os (As) gestores (as), no trabalho de articulação e parceria com a comunidade escolar, devem oportunizar a participação dos segmentos envolvidos com os processos educativos e envolvê-los na construção de projetos coletivos que positivem a diversidade étnico-racial e oportunize que todos (as) se sintam incluídos (as), reconhecidos (as) e respeitados (as).

Santos (2015) mostra que o princípio da diversidade racial nas práticas de gestão educacional para a primeira infância se desenha como uma resistência, uma dificuldade, um desafio para aqueles/as que assumem essa função - as/os gestoras/es de escolas de 
educação infantil. E que as dificuldades e desafios são fruto da naturalização da desigualdade racial brasileira, o que dificulta o combate às práticas racistas no interior da escola.

Os cursos de Pedagogia, enquanto espaço de formação desses (as) profissionais, devem abordar a temática da educação das relações étnico-raciais como elemento estruturante das suas propostas pedagógicas, curriculares e das ações que realizam, como parte do compromisso com a superação do racismo e estarem abertos a novas possibilidades de diálogos com os movimentos negros e com os territórios que preservam o legado afrodiaspórico.

Com isso, é necessário repensar os referenciais teóricos e metodológicos que dão base à formação dos profissionais que terão à responsabilidade de cuidar da educação das crianças da educação infantil, dos anos iniciais do ensino fundamental, bem como dos profissionais que atuarão na gestão dos processos educativos e nas políticas educacionais.

\section{PROPOSIÇÕES TEÓRICO-METODOLÓGICAS PARA A ÁREA DA PEDAGOGIA}

A discussão sobre ERER na formação inicial e continuada dos (as) pedagogos (as) traz em si o compromisso político de construção de proposições teórico-metodológicas para a área que leve em conta a diversidade dos sujeitos que são afetados pela educação. Por um lado, pedagogos (as) em formação, majoritariamente mulheres, negras, pobres e da periferia; por outro lado, estudantes da escola pública com um perfil semelhante - meninas e meninos negros, pobres e também da periferia. Gomes (2017, p. 135) coloca a possibilidade de novos horizontes emancipatórios e desafia a construção de uma pedagogia da diversidade (de raça, de gênero, de idade, de culturas) considerada como resultado da luta contra hegemônica que está no cerne do processo de emancipação social da educação.

A compreensão dos saberes produzidos, articulados e sistematizados pelo Movimento Negro tem a capacidade de subverter a teoria educacional, construir a pedagogia das ausências e das emergências, repensar a escola, descolonizar os currículos. Ela poderá nos levar ao necessário movimento de descolonização do conhecimento. (GOMES, 2017, p. 139).

No campo da Pedagogia, a literatura infantil, a poesia, a música, as artes de uma forma geral, a relação com a produção dos movimentos negros e das comunidades tradicionais podem ser caminhos possíveis de (re) conexão com a África e com o legado afrodiaspórico. No entanto, é preciso que se repense a organização do trabalho pedagógico 
das escolas numa perspectiva antirracista que rompa com a lógica do racismo institucional (DIAS, 2012). No contexto do trabalho pedagógico com as primeiras infâncias, a autora propõe princípios pedagógicos de um trabalho com a abordagem da diversidade étnico-racial, quais sejam: a "coragem" para enfrentar o tema, a ludicidade, a diferença entre as pessoas como um valor positivo e, por fim, a criança precisa de elementos que colaborem na construção de sua identidade racial de modo positivo.

Nessa reflexão a autora parte de duas experiências de formação de professores de educação infantil realizadas em Campo Grande/MS, em 2001, e um curso ocorrido em Campinas/São Paulo numa parceria da Secretaria de Educação com a ONG Centro de Estudos das Relações de Trabalho e Desigualdades (CEERT) para propor reflexões significativas no campo da formação docente; defende que essas experiências ampliam os modos de atuar dos (as) professores (as) e influenciam a dinâmica do ensino-aprendizagem nas diversas áreas do conhecimento. A experiência escolar deve servir para ampliar e intensificar a socialização da criança com o mundo tendo como aspecto importante o reconhecimento positivo da diversidade que deve estar presente no seu processo de formação desde os primeiros anos de vida.

Uma ação conjunta que deve se dar de forma articulada entre universidades, secretarias de educação, movimentos negros, escolas, famílias, tal como preconiza as Diretrizes Curriculares Nacionais para a Educação das Relações Étnico-Raciais e para o ensino de História e Cultura Afro-Brasileira e Africana (2004) e o Plano Nacional de implementação das diretrizes curriculares nacionais para a educação das relações étnico-raciais e para o ensino de história e cultura afro-brasileira e africana (2009), reiterando o que diz o provérbio africano: "É necessário uma aldeia inteira para educar uma criança."

Petit $(2015,2016)$ propõe uma educação afro referenciada fundada nos princípios da pretagogia onde o corpo atua como fonte e produtor do conhecimento e a autobiografia seja tratada como elemento importante na busca das histórias africanas que nos envolvem e marcam. A proposta, segundo a autora, é que o nosso pertencimento se situe em uma linhagem biológica e/ou simbólica/espiritual, pois se trata fundamentalmente de relação de ancestralidade cultural. Nesse contexto, a tradição oral em toda a sua dimensão tem uma importância. Segundo Bâ (2010, p. 169), para um tradicionalista africano, a tradição oral é o "conhecimento total":

Nas tradições africanas - pelo menos nas que conheço e que dizem respeito a toda a região de savana ao sul do Saara -, a palavra falada se empossava, além de um valor moral fundamental, de um caráter sagrado vinculado à sua origem divina e às forças ocultas nela depositadas. 
Desse modo, a tradição oral tem como marca fundamental o processo de transferência desse conhecimento entre as gerações, que nos remete às diferentes formas de se relacionar com o mundo, as diferentes experiências de vida, sendo, portanto, importantes nos processos de ressignificação do ensino. Petit (2016, p. 662) sugere ainda um trabalho com diversas abordagens da literatura oral, em especial, os ensinamentos milenares como os "[...] mitos, contos, provérbios e simbologias adinkras (ideogramas tradicionais da cultura acã, em Gana)", inclusive o Sankofa traduzido como "retornar ao passado para ressignificar o presente e construir o futuro" e nesse sentido as ações do presente e os projetos de futuro devem ser elaboradas a partir dos conhecimentos produzidos pela ancestralidade. Essa reflexão nos remete à importância do reconhecimento dos conhecimentos da tradição oral e da amplitude do patrimônio afro-brasileiro como fundamentais nos processos de formação.

Para Rodrigues, Cardoso e Silva (2019) os debates e desdobramentos das ações afirmativas no campo da formação de professores (as) ainda se constituem como desafios, sendo fundamental que a universidade enquanto espaço intelectual, científico, educativo e político supere o padrão desigual e discriminatório das relações étnico-raciais no seu ambiente cotidiano. Nesse processo, é necessário influenciar os currículos dos cursos de formação de professores (as), os procedimentos de pesquisa, as relações pedagógicas e convívio no ambiente acadêmico com referências teóricas de matrizes étnico-raciais diversas.

É nesse contexto que se espera que os cursos de Pedagogia que têm como um dos seus compromissos importantes formar os (as) professores (as) da educação infantil e dos anos iniciais do ensino fundamental, bem como os (as) gestores (as) escolares, possam repensar as bases de pensamento dessa formação em face dos desafios postos nas determinações legais que dão base à uma política educacional antirracista.

\section{CONSIDERAÇÕES FINAIS}

0 artigo buscou analisar a importância das relações étnico-raciais na formação de professoras e professores, a partir dos pressupostos do corpo legal que deve fundamentar a política educacional antirracista no Brasil: LDB 9.394/96 alterada pelas Leis $n^{\circ}$. 10.639/03 e $n^{\circ}$. 11.645/08, das Diretrizes Curriculares Nacionais para a Educação das Relações ÉtnicoRaciais para o Ensino de História e Cultura Afro-brasileira e Africana (2004), do Resolução $n^{\circ}$. 01/2004 do Conselho Nacional de Educação, do Plano Nacional de implementação das Diretrizes Curriculares Nacionais para a Educação das Relações Étnico-Raciais e para o ensino de História e Cultura Afro-Brasileira e Africana (2009). 
É nesse contexto de proposição de mudanças curriculares, requeridas pelos movimentos sociais negros, que clama pelo combate ao racismo, que espera-se que os cursos de Pedagogia que têm como um dos seus compromissos importantes formar os(as) professores(as) da educação infantil e dos anos iniciais do ensino fundamental, bem como os(as) gestores(as) escolares, possam repensar as bases de pensamento dessa formação em face dos desafios postos nas determinações legais que poderão materializar uma política educacional antirracista.

Para que o antirracismo seja incorporado nos discursos e nas práticas institucionais, na universidade, serão necessários o investimento na criação de disciplinas específicas nas estruturas dos cursos de licenciaturas e também nos bacharelados, no fortalecimento dos grupos de pesquisa e estudo, na proposição de mais congressos acadêmicos que abordem as temáticas, na ampliação das linhas de pesquisa nos programas de pós-graduação e outras experiências transversais que possam se somar no combate ao racismo e na inclusão de mais autoras e autores negros não somente no currículo, nas práticas extensionistas e nas pesquisas acadêmicas propostas pela comunidade universitária, bem como na defesa do potencial transformador das ações afirmativas.

Além disso, é importante priorizar os processos de formação docente, que possam atuar em escolas e universidades, sempre atentos ao legado afrodiaspórico do passado e do presente, às transformações vivenciadas nas sociedades contemporâneas, à toda a produção de conhecimento protagonizada por ativistas dos movimentos negros e pesquisadores (as) comprometidos (as) com essas pautas. É preciso estar atento às produções nesse campo e oportunizar reflexões que se voltam para o campo da educação e seus profissionais a repensar suas formações, suas práticas e a sua própria existência.

\section{REFERÊNCIAS}

BÂ, H. A. A tradição viva. Metodologia e pré-história da África. Edição: Joseph Ki-Zerbo. 2. ed. rev. Brasilia, DF: UNESCO, 2010.

BRASIL. Lei n. 9.394, de 20 de dezembro de 1996. Estabelece as Diretrizes e Bases da Educação Nacional. Diário Oficial da União, Brasilia, DF, 21 dez. 1996. Disponível em: http://www.planalto.gov.br/ ccivil_03/Leis/L9394.htm. Acesso em: 15 jul. 2020.

BRASIL. Lei $n$. 10.639, de 9 de janeiro de 2003. Altera a lei n 9.394, de 20 de dezembro de 1996, que estabelece as diretrizes e bases da educação nacional, para incluir no currículo oficial da rede de ensino a obrigatoriedade da temática "História e Cultura Afro-brasileira", e dá outras providências. Diário Oficial da União, Brasilia, DF, 10 jan. 2003. Disponivel em: http://www.planalto. gov.br/ccivil_03/ leis/2003/110.639.htm. Acesso em: 17 out. 2020. 
BRASIL. Lei n. 11.645, de 10 de março de 2008. Altera a lei n 9.394, de 20 de dezembro de 1996, que estabelece as diretrizes e bases da educação nacional, para incluir no currículo oficial da rede de ensino a obrigatoriedade da temática "História e Cultura Afro-brasileira e Indígena", e dá outras providências. Diário Oficial da União, Brasilia, DF, 11 mar. 2008. Disponivel em: http://www.planalto. gov.br/ ccivil_03/_ato2007-2010/2008/lei/111645.htm. Acesso em: 18 nov. 2020.

BRASIL. Ministério da Educação. Conselho Nacional de Educação. Parecer CNE/CP n 3, de 10 de março de 2004. Institui as Diretrizes Curriculares Nacionais para a Educação das Relações Étnico-Raciais e para o Ensino de História e Cultura Afro-Brasileira e Africana. Diário Oficial da União, Brasília, DF, 10 mar. 2004.

BRASIL. Ministério da Educação. Conselho Nacional de Educação. Resolução CNE/CP nº 01, de 15 de maio de 2006. Institui Diretrizes Curriculares Nacionais para o Curso de Graduação em Pedagogia, Licenciatura. Brasília, DF: MEC, 2006.

BRASIL. Ministério da Educação. Conselho Nacional de Educação. Resolução CNE/CP n. 01, de 17 de junho de 2004. Institui Diretrizes Curriculares Nacionais para a Educação das Relações Étnico-Raciais e para o Ensino de História e Cultura Afro-Brasileira e Africana. Brasília, DF: MEC, 2004.

BRASIL. Ministério da Educação. Secretaria de Educação Continuada, Alfabetização e Diversidade. Plano Nacional de implementação das Diretrizes Curriculares Nacionais para a Educação das Relações Étnico-Raciais e para o ensino de História e Cultura Afro-Brasileira e Africana. Brasilia, DF: MEC, 2009.

CARNEIRO, A. S. A construção do outro como não-ser como fundamento do ser. 2005. $339 \mathrm{f}$. Tese (Doutorado em Educação) - Faculdade de Educação, Universidade de São Paulo, São Paulo, 2005.

COELHO, W. de N. B.; COELHO, M. C. Os conteúdos étnico-raciais na educação brasileira: práticas em curso. Educar em Revista, n. 47, p. 67-84, jan./mar. 2013.

COELHO, W. de N. B. Formação de professores e relações étnico-raciais (2003-2014): produção em teses, dissertações e artigos. Educ. rev., v. 34, n. 69, p. 97-122, jun. 2018. Disponivel em: http://www. scielo.br/scielo. php?script=sci_arttext\& pid=S0104-40602018000300097\&lng=en\&nrm=iso. Acesso em: 30 ago. 2020.

CORENZA, J. de A. Formação inicial de professores: conversas sobre relações raciais e educação. Curitiba: Appris, 2018.

DAMIÃO, F. de J.; ARAÚJO, R. C. Culturas e infâncias negras pequenas: uma pauta das intelectuais negras na academia. In: CONGRESSO BAIANO DE PESQUISADORES(AS) NEGROS(AS), 9., 2019, Salvador. Anais [...] Salvador, 2019.

DIAS, L. R. Formação de professores, educação infantil e diversidade étnico-racial: saberes e fazeres nesse processo. Revista Brasileira de Educação, v. 17, n. 51, set./dez. 2012. 
GOMES, N. L. Limites e Possibilidades da implementação da Lei 10.639/03 no contexto das políticas públicas em educação. In: PAULA, M. de; HERINGER, R. (org.). Caminhos Convergentes: estado e sociedade na superação das desigualdades raciais no Brasil. Rio de Janeiro: Fundação Heinrich Boll Actioonaid, 2009.

GOMES, N. L. 0 Movimento Negro Educador. Petrópolis, RJ: Vozes, 2017.

GOMES, N. L. Relações étnico-raciais, educação e descolonização dos currículos. Currículo sem fronteiras, v. 12, n. 1, p. 98-109, jan./abr. 2012.

GONÇALVES E SILVA, P. Aprender, ensinar e relações étnico-raciais no Brasil. Educação, ano 30, n. 3 (63), p. 489-506, set./dez. 2007.

GONÇALVES, L. R. D. Políticas curriculares e descolonização dos currículos: a lei 10.639/03 e os desafios para a formação de professores. Revista Educação e Poĺticas em Debate, v. 2, n. 1, jan./jul. 2013

LUZ, I. M. No interior da memória: caminhos, símbolos e fontes de um passado afro-brasileiro. In: NUNES, C.; REIS, M. da C. Dossiê Abordagens pedagógicas interdisciplinares para a educação das relações étnico-raciais. Revista Debates em Educação, v. 11, n. 23, jan./abr. 2019.

MACEDO, M. de L. Tradição oral afro-brasileira e escola: um diálogo possível? In: OLIVEIRA, I. de; SILVA, P. B. G.; PINTO, R. P. (org.). Negro e educação: escola, identidades, cultura e políticas públicas. São Paulo: Ação educativa/ANPED, 2005.

PASSOS, J. C. dos. As relações étnico-raciais nas licenciaturas: o que dizem os currículos anunciados. Poiésis, v. 8, n. 13, p. 172-188, jan./jun. 2014.

PETIT, S. H. Práticas pedagógicas para a Lei $n^{\circ}$. 10.639/03: a criação de nova abordagem de formação na perspectiva das africanidades. Educ. Foco, v. 21, n. 3, p. 657-684, set./dez. 2016.

PETIT, S. H. Pretagogia: pertencimento, corpo-dança afroancestral e tradição oral Africana na formação de professoras e professores. 1. ed. Fortaleza: EDUECE, 2015.

RODRIGUES, T. C.; CARDOSO, I. A.; SILVA, A. R. Ações afirmativas e formação de professores: diálogos e perspectivas a partir do NEAB/UFSCar. Roteiro, v. 44, n. 2, p. 1-24, maio/ago. 2019.

SANTOS, M. A. dos. A primeira Infância Negra e a Gestão das Instituições de Educação Infantil. Pontos de Interrogação - Revista de Crítica Cultural, v. 5, n. 2, jul./dez. 2015.

VIDEIRA, P. L. Marabaixo, dança afrodescendente: ressignificando a identidade étnica do negro amapaense. Fortaleza: Edições UFC, 2009.

Endereço para correspondência: Rua Afro Tavares Campos, 600, Muriti, 63132-710, Crato, Ceará, Brasil; cicera.nunes@urca.br 
